\title{
Grassland coverage inter-annual variation and its coupling relation with hydrothermal factors in China during 1982-2010
}

\author{
ZHOU Wei ${ }^{1}$, GANG Chengcheng ${ }^{1}$, CHEN Yizhao ${ }^{1}$, MU Shaojie ${ }^{1}$, \\ SUN Zhengguo ${ }^{2},{ }^{*}$ LI Jianlong ${ }^{1}$ \\ 1. School of Life Science, Nanjing University, Nanjing 210093, China; \\ 2. College of Animal Sciences, Nanjing Agricultural University, Nanjing 210095, China
}

\begin{abstract}
GIMMS (Global Inventory Modeling and Mapping Studies) NDVI (Normalised Difference Vegetation Index) from 1982 to 2006 and MODIS (Moderate Resolution Imaging Spectroradiometer) NDVI from 2001 to 2010 were blended to extract the grass coverage and analyze its spatial pattern. The response of grass coverage to climatic variations at annual and monthly time scales was analyzed. Grass coverage distribution had increased from northwest to southeast across China. During 1982-2010, the mean nationwide grass coverage was $34 \%$ but exhibited apparent spatial heterogeneity, being the highest $(61.4 \%)$ in slope grasslands and the lowest $(17.1 \%)$ in desert grasslands. There was a slight increase of the grass coverage with a rate of $0.17 \%$ per year. Increase in slope grasslands coverage was as high as $0.27 \%$ per year, while in the plain grasslands and meadows the grass coverage increase was the lowest (being $0.11 \%$ per year and $0.1 \%$ per year, respectively). Across China, the grass coverage with extremely significant increase $(P<0.01)$ and significant increase $(\mathrm{P}<0.05)$ accounted for $46.03 \%$ and $11 \%$ of the total grassland area, respectively, while those with extremely significant and significant decrease accounted for only $4.1 \%$ and $3.24 \%$, respectively. At the annual time scale, there are no significant correlations between grass coverage and annual mean temperature and precipitation. However, the grass coverage was somewhat affected by temperature in alpine and sub-alpine grassland, alpine and sub-alpine meadow, slope grassland and meadow, while grass coverage in desert grassland and plain grassland was more affected by precipitation. At the monthly time-scale, there are significant correlations between grass coverage with both temperature and precipitation, indicating that the grass coverage is more affected by seasonal fluctuations of hydrothermal conditions. Additionally, there is one-month time lag-effect between grass coverage and climate factors for each grassland types.
\end{abstract}

Keywords: grass coverage; climate factors; spatial-temporal dynamic; correlation; time lag effect

Received: 2013-12-27 Accepted: 2014-01-22

Foundation: The National Natural Science Foundation of China, No.41271361; National Basic Research Program of China, No.2010CB950702; The APN Projects, No.ARCP2013-16NMY-Li; The Public Sector Linkages Program supported by AusAID, No.64828; China's High-tech Special Projects, No.2007AA10Z231

Author: Zhou Wei (1985-), PhD, specialized in application of remote sensing and terrestrial ecosystem carbon cycle. E-mail: zhouw866@163.com

"Corresponding author: Li Jianlong, Professor, E-mail: jianlongli@gmail.com,j1li2008@nju.edu.cn 


\section{Introduction}

Response of terrestrial ecosystems to global climate change is one of the most complex research topics in the global change studies (Waker et al., 1997). Vegetation, as the main component of terrestrial ecosystem, is sensitive to climatic change. Climate change has caused the change of vegetation growth environment, and then impacted vegetation dynamic, composition, and functions (Parmesan et al., 2003; Xin et al., 2008; Roerink et al., 2003; Keeling et al., 1996; Weltzin et al., 2003). Vegetation coverage is an important ecological parameter, which reflects the degree of lush vegetation and the photosynthetic area. Its variations are the direct results of regional environmental change (Xin et al., 2007), and it executes an important indication function of regional environmental change (Gan et al., 2011). Researches on the response of plant growth to climate change have been widely conducted based on normalized difference vegetation index (NDVI) (Hall et al., 1992; Li et al., 2000). Global warming has led to significant enhancement of vegetation activity in the high latitudes of Northern Hemisphere (Zhou et al., 2001; Myneni et al., 1997). In China, vegetation activity in most regions also increased, especially in the Tibetan Plateau, Northwest China, and North China (Fang et al., 2003; Li et al., 2006; Piao et al., 2001; Zhang et al., 2006). Although researches on the response of vegetation growth to temperature and precipitation are widely conducted, the conclusions of the correlations between vegetation growth and hydrothermal factors are inconsistent. Some scholars argued that precipitation was an important factor responsible for the vegetation growth and seasonal variations in China (Zhao et al., 2001; Tang et al., 2003; Sun et al., 2010; Dai et al., 2011; Sun et al., 2013); others found that the effects of temperature to vegetation growth were even larger than precipitation (Wu et al., 2009; Luo et al., 2009; Sun et al., 1998; Cui et al., 2009). Response of different vegetation types to hydrothermal factors is different and the impacts of precipitation and temperature on vegetation coverage also varied for different spatial and temporal scales and ecosystem types. For example, for the desert grassland in North China, precipitation serves as a restrictive factor (Li et al., 2000).

Grassland is the biggest terrestrial ecosystem type in China and has an important role in the national ecological environmental protection plans (Ren et al., 2011). In the recent decades, with the intensification of global climate change and human interference, grassland ecosystem has also significantly changed. At present, studies of the correlation between grass coverage and climate change are mainly focused on selected specific regions and on short-term time scale (Zhang et al., 2011; Mu et al., 2013). Little research was done on the spatial-temporal dynamics of the grass coverage and on its correlation with climate change at national scale and on longer time scale. Grasslands accounting for one third of China's total land area, mainly distributes in the northwestern arid and semi-arid climatic zones, and in and around the Tibetan Plateau. These regions are more sensitive to global change (Christensen et al., 2004). Therefore, the research on the grass coverage dynamics and its response to climate change in China, will contribute to our understanding of impacts of climate change on terrestrial ecosystem.

In this study, GIMMS (Global Inventory Modeling and Mapping Studies) NDVI (Normalised Difference Vegetation Index) from 1982 to 2006 and MODIS (Moderate Resolution Imaging Spectroradiometer) NDVI from 2001 to 2010 were used to calculate grass coverage 
有 and their spatial-temporal dynamics. Finally, the correlations between grass coverage and climate factors at annual and monthly time-scales were analyzed. This study aims to explore the effects of climate change on vegetation growth and find the climatic restrictive factors for each grassland type. Understanding of these effects provides some theoretical basis and is essential for reliable projections of the grassland ecosystem change in the future climate change.

\section{Materials and methods}

\subsection{Normalized difference vegetation index (NDVI)}

The Advanced Very High-Resolution Radiometer (AVHRR) GIMMS-NDVI data, with a resolution of $8 \mathrm{~km} \times 8 \mathrm{~km}$, covers the periods from January 1982 to December 2006. Data are available at http://westdc.westgis.ac.cn/data/ with a 15-day time resolution. During the preparing of the dataset, its creators conducted the radiation correction, geometrical correction, and cloud filtering to improve the data accuracy. At present, this dataset has been widely used in numerous larger-scale land cover variations studies (Zhao et al., 2001).

MODIS-derived 16-day composite atmospherically corrected maximal vegetation indices (MOD13A1) with $500 \mathrm{~m} \times 500 \mathrm{~m}$ spatial resolution were downloaded from the Earth Observing System data gateway (http://edcimswww.cr.usgs.gov/pub/imswelcome/) from 2001 to 2010. Both NDVI image datasets were converted to Albers equal area conical projection and WGS-84 datum using the ArcGIS V9.3 software (ESRI, California, USA). To reduce the image noise from the atmospheric clouds, particles, shadows, etc., the three-point smoothing was used to improve NDVI data quality (Chen et al., 2000). The maximum value composite (MVC) was used to produce monthly NDVI from 15-day and 16-day NDVI datasets for the entire 1982-2010 period.

In order to create a long time series of NDVI dataset from 1982 to 2010, a regression model was applied based on the two kinds of NDVI sources. Firstly, the GIMMS-NDVI dataset was re-sampled into MODIS-NDVI of $1 \mathrm{~km}$ spatial resolution using the nearest neighbor method to resolve the different spatial resolutions of both datasets. The correlation between maximum GIMMS NDVI and MODIS NDVI were calculated for 2004, 2005 and 2006 (they are $0.90,0.91$, and 0.89 , respectively and has highly statistically significant at the 0.001 level). Regression equation between the two kinds of NDVI datasets of 2005 was as follows:

$$
\mathrm{NDVI}_{\text {GIMMS }}=0.7629 \mathrm{NDVI}_{\text {MODIS }}+0.0454
$$

(Sample size is $117422, \mathrm{R}^{2}=0.8084$, RMSE $=0.08$; Figure 1).

This regression equation was used to prolong the NDVI time series from 1982 to 2010.

\subsection{Meteorological data}

Meteorological data from 1982 to 2010, including monthly mean temperature and total precipitation for 720 stations, were obtained from China Meteorological Data Sharing Service System (http://cdc.cma.gov.cn/home.do). Ordinary Kriging interpolation was used to interpolate the meteorological data into grid at $1 \mathrm{~km} \times 1 \mathrm{~km}$ spatial resolution and with the same 
coordinate system as the NDVI images. In addition, the error analysis of interpolated meteorological data was conducted by comparison with actual measurements (Table 1). Results indicated that there was no significant difference between measured and interpolated data and the RMSE (Root mean square error) of the estimates were less than $1^{\circ} \mathrm{C}$ for monthly temperature and $2 \mathrm{~mm}$ for monthly precipitation (Table 1).

\subsection{Land cover products}

The Global Land Cover 2000 dataset (GLC 2003) with $1 \mathrm{~km}$ spatial resolution indicated that China's grassland area accounts for approximately 35\% of China's total land area, mainly distrib

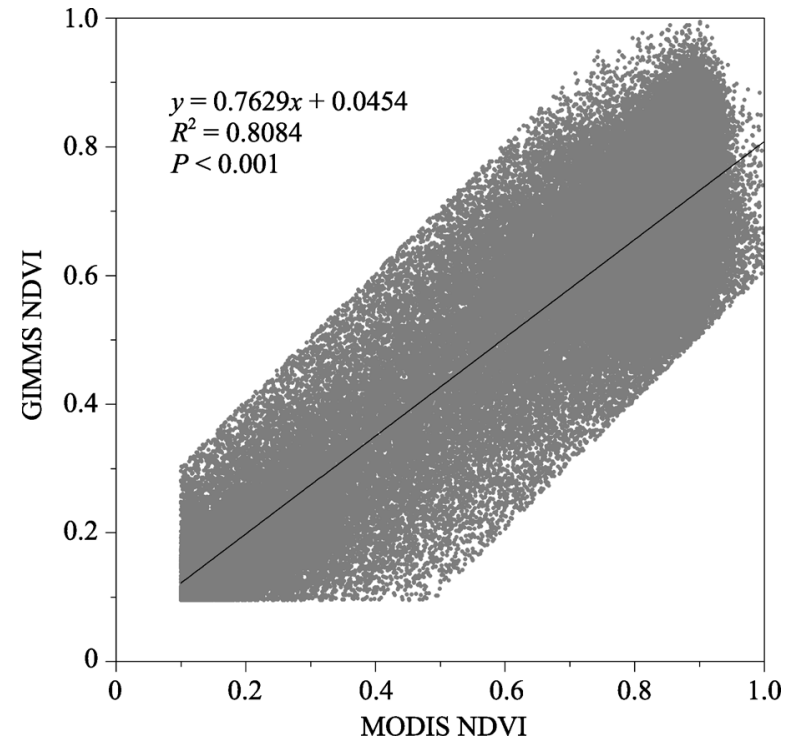

Figure 1 The regression analysis between MODIS NDVI and GIMMS NDVI present, grassland reclassification accuracy of GLC2000 for China is higher than other land cover products such as IGBP-DISCover (International Geosphere Biosphere Programme global land cover datasets), UMD(the University of Maryland) global land cover map, and MODIS global land cover map (Ran et al., 2010). Besides, GLC2000 product has the highest consistency with the China vegetation cover data at a scale of 1:100 000, and has six grassland types (Figure 2).

Table 1 Error analysis for the interpolated meteorological data, using year 2001 as an example

\begin{tabular}{|c|c|c|c|c|c|c|}
\hline \multirow{2}{*}{ Month } & \multicolumn{3}{|c|}{ Temperature $\left({ }^{\circ} \mathrm{C}\right)(n=720)$} & \multicolumn{3}{|c|}{ Precipitation $(\mathrm{mm})(n=720)$} \\
\hline & Mean error & RMSE & $R^{2}$ & Mean error & RMSE & $R^{2}$ \\
\hline Jan & 0.006 & 0.958 & 0.958 & 0.289 & 0.987 & 0.809 \\
\hline Feb & -0.073 & 0.985 & 0.935 & 0.351 & 1.425 & 0.815 \\
\hline Mar & -0.115 & 0.937 & 0.859 & 0.509 & 0.958 & 0.931 \\
\hline Apr & -0.136 & 0.883 & 0.821 & 3.149 & 1.491 & 0.799 \\
\hline May & -0.124 & 0.925 & 0.842 & 0.438 & 1.677 & 0.839 \\
\hline Jun & -0.108 & 0.960 & 0.869 & 1.758 & 0.975 & 0.877 \\
\hline Jul & -0.113 & 0.883 & 0.894 & -10.026 & 1.709 & 0.841 \\
\hline Aug & -0.095 & 0.908 & 0.886 & -7.659 & 1.506 & 0.792 \\
\hline Sep & -0.098 & 0.976 & 0.893 & -4.742 & 0.997 & 0.828 \\
\hline Oct & -0.085 & 0.950 & 0.897 & 2.768 & 1.302 & 0.817 \\
\hline Nov & 0.028 & 0.875 & 0.927 & 0.481 & 1.146 & 0.784 \\
\hline Dec & 0.008 & 0.887 & 0.953 & -0.447 & 1.030 & 0.803 \\
\hline
\end{tabular}




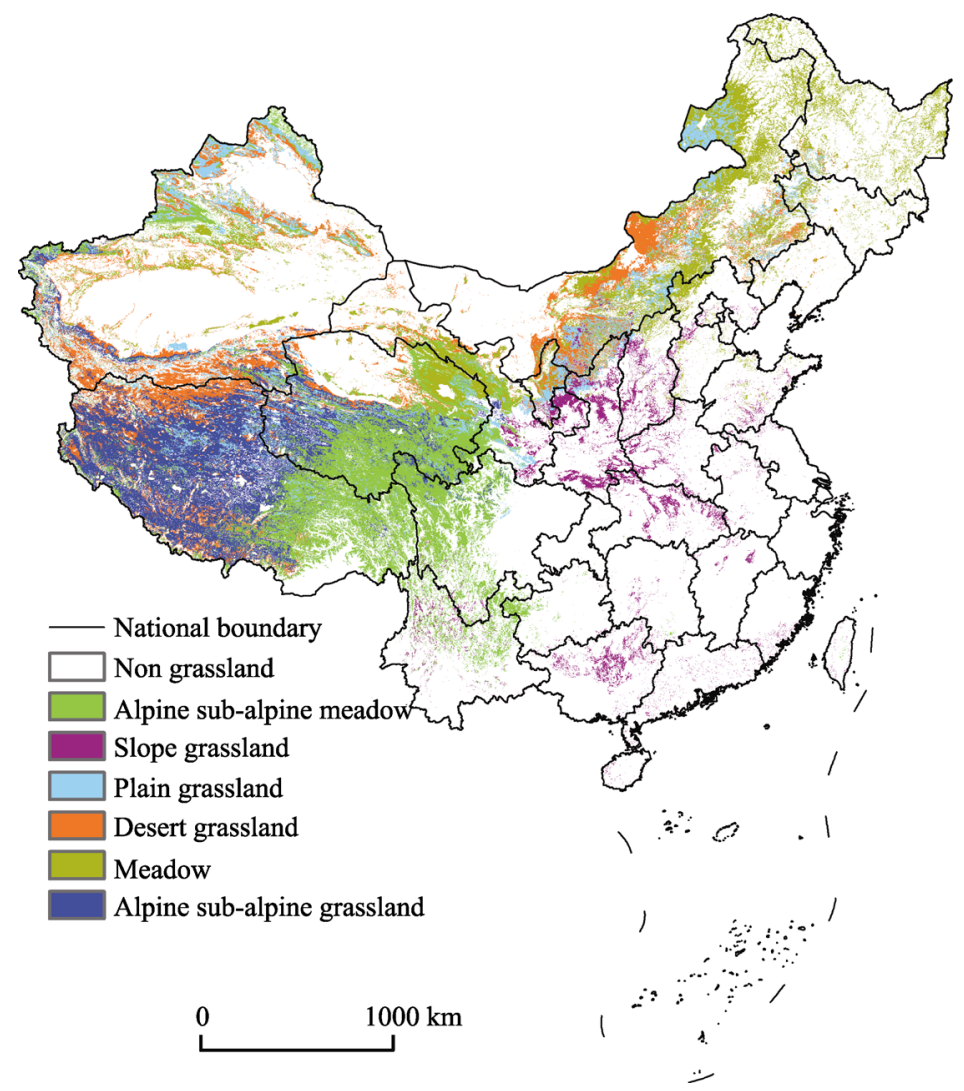

Figure 2 Location of the study area and its grassland type distribution

\subsection{Estimation of grass coverage and its accuracy validation}

\subsubsection{Vegetation coverage estimation}

Gutman and Ignatov (1998) developed a semi-empirical relationship between vegetation coverage and NDVI, and proposed a dense vegetation mosaic-pixel model to derive vegetation coverage from NDVI. The model of the calculation of vegetation coverage can be expressed as:

$$
N D V I=N D V I_{v} C_{i}+N D V I_{s}\left(1-C_{i}\right)
$$

where $N D V I_{s}$ is the minimum NDVI corresponding to $0 \%$ vegetation cover or bare soil and $N D V I_{v}$ is the maximum one with a $100 \%$ vegetation cover. The vegetation coverage $\left(C_{i}\right)$ derived by the scaled NDVI can be expressed as:

$$
C_{i}=\frac{N D V I-N D V I_{\min }}{N D V I_{\max }-N D V I_{\min }}
$$

where $N D V I_{\max }$ and $N D V I_{\min }$ stand for the maximum and minimum NDVI of a year, respectively.

\subsubsection{Accuracy validation of vegetation coverage}

To validate the accuracy of the vegetation coverage, we sampled 90 sites across the study 


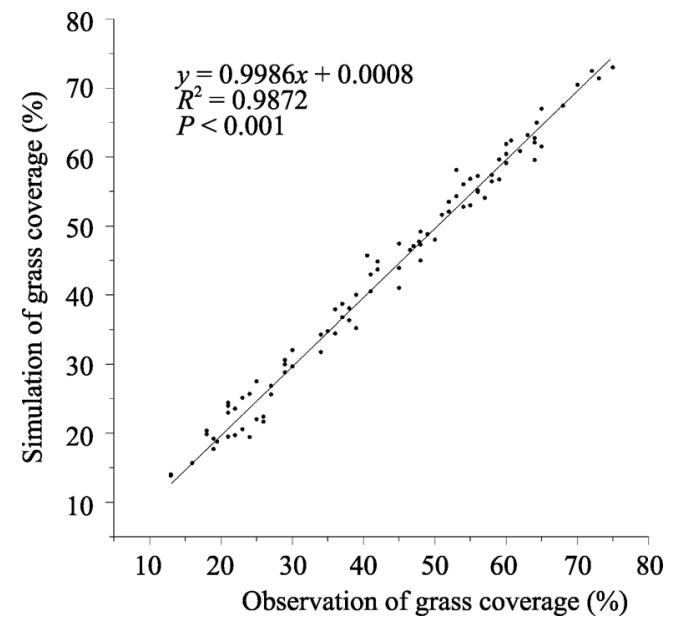

Figure 3 Correlation analysis of the estimated grass coverage and its field observed values

area in July and August of 2009. At each site $(10 \mathrm{~m} \times 10 \mathrm{~m})$, five plots $(1 \mathrm{~m} \times 1 \mathrm{~m})$ were set, and vegetation coverage was investigated; mean coverage of these five plots was considered as sites vegetation coverage. Correlation between estimated grass coverage and field observation values are shown in Figure 3 $\left(\mathrm{R}^{2}=0.9872, \mathrm{P}<0.001\right)$, which indicates that the correlation is significant and the estimates results are reliable.

\subsection{Grassland vegetation coverage trend analysis}

Simple linear regression was used to analyze changing trend of vegetation cover from 1982 to 2010. Simple linear regression estimates the changing tendency for each grid as follows:

$$
\theta_{\text {Slope }}=\frac{n \times \sum_{\mathrm{i}=1}^{n} i \times C_{i}-\left(\sum_{i=1}^{n} i\right)\left(\sum_{i=1}^{n} C_{i}\right)}{n \times \sum_{i=1}^{n} i^{2}-\left(\sum_{i=1}^{n} i\right)^{2}}
$$

where $n$ is the number of studied years; $C_{i}$ is the maximum vegetation coverage of year $i$; $\theta_{\text {Slope }}$ is the slope of the trend line. To check the significance of the change tendency of coverage, a significance test (F-test) was applied. The F statistic test is shown by equation 4 :

$$
F=U \times \frac{n-2}{Q}
$$

where $U=\sum_{i=1}^{n}\left(\hat{y}_{i}-\bar{y}\right)^{2}$ is the regression sum of squares, $Q=\sum_{i=1}^{n}\left(y_{i}-\hat{y}_{i}\right)^{2}$ is residual sum of squares; $y_{i}$ is the estimated value of vegetation coverage for year $i$ and $\hat{y}_{i}$ is the regression value; $\bar{y}$ is the average value of annual vegetation coverage from 1982 to $2010 ; n$ is the sample size (here, $n=29$ ). According to the F-test, the changing tendency was classified into 6 categories: extremely significant decrease (ESD, $\theta_{\text {Slope }}<0, \mathrm{P}<0.01$ ); significant decrease (SD, $\theta_{\text {Slope }}<0,0.01<\mathrm{P}<0.05$ ); no significant decrease (NSD, $\theta_{\text {Slope }}<0, \mathrm{P}>0.05$ ); no significant increase (NSI, $\theta_{\text {Slope }}>0, \mathrm{P}>0.05$ ); significant increase (SI, $\theta_{\text {Slope }}>0,0.01<\mathrm{P}<0.05$ ); extremely significant increase (ESI, $\left.\theta_{\text {Slope }}>0, \mathrm{P}<0.01\right)$.

\subsection{Correlation analysis of grass coverage and climate factors}

To explore the response of grass coverage to climate change, correlation coefficients between vegetation coverage and annual (monthly) mean temperature and total precipitation were calculated by the following equation: 


$$
R_{x y}=\frac{\sum_{i=1}^{n}\left[\left(x_{i}-\bar{x}\right)\left(y_{i}-\bar{y}\right)\right]}{\sqrt{\sum_{i=1}^{n}\left(x_{i}-\bar{x}\right)^{2} \sum_{i=1}^{n}\left(y_{i}-\bar{y}\right)^{2}}}
$$

where $R_{x y}$ is the correlation coefficient of variable $x$ and $y ; x_{i}$ is the vegetation coverage of the $i$ th year or month; $y_{i}$ is the temperature or precipitation of the $i$ th year or month; $\bar{x}$ is the average vegetation coverage for all years or months, $\bar{y}$ is the average temperature or precipitation for all years or months; and $i$ is the number of years or months. Applying the non-autocorrelation clause for inter-annual variations of grass coverage, we assume that its major variations occur in the warm season and, therefore, the grass coverage time series should be not-auto correlated at the annual time scale.

\section{Results}

\subsection{Spatial distribution of long-term mean grass coverage}

The spatial distribution of long-term mean grass coverage in China is shown in Figure 4a. The grass coverage value is relative higher in Southeast China, while lower in Northwest China. For the entire grassland, the mean grass coverage for the 1982-2010 period was 34\% with the highest in the slope grassland and the lowest in desert grassland (Figure 4b).
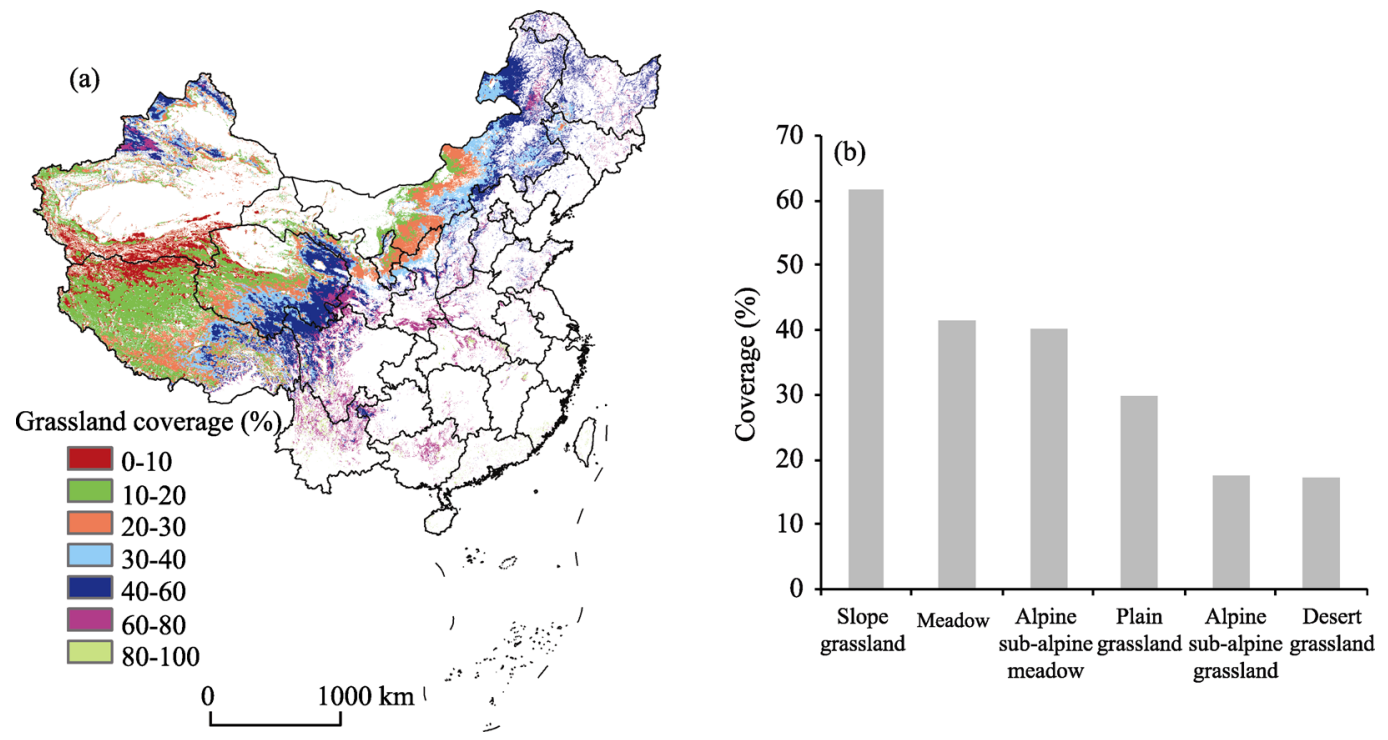

Figure 4 Spatial distribution of the mean grass coverage from 1982 to 2010 in China

The slope grasslands are mainly located in the Qinling Mountains, north of Guangxi Zhuang Autonomous Region, and west of Jilin Province, with abundant precipitation and lush vegetation. The mean grass coverage of slope grassland was $61.4 \%$ during the 29 years, which ranged from $60 \%$ to $80 \%$. The meadow grasslands mainly distribute in the northeast of Inner Mongolia Autonomous Region (IM), west of Heilongjiang and Jilin provinces, as well as the Qilian Mountain region. The mean grass coverage of meadow grasslands was $41.5 \%$, which varies between $40 \%$ and $60 \%$. For alpine and sub-alpine meadow grassland 
type, the mean grass coverage was $40.1 \%$. This grasslands type is located in the south of Tibet Autonomous Region, Qilian Mountains, southern slopes of the Tianshan Mountains, and the Altai Mountains. Here, the grass coverage decreased from southeast to northwest and ranged from $30 \%$ to $60 \%$. Plain grasslands, with the mean vegetation coverage of $29.8 \%$, were located in Hulun Buir region, central part of IM and the south of Ningxia Hui Autonomous Region with coverage ranging from $20 \%$ to $40 \%$. In alpine and sub-alpine grasslands, the mean grass coverage was $17.5 \%$. These grasslands mainly distributed in the west of Tibet Autonomous Region and the west of Qinghai Province with coverage between $10 \%$ and $30 \%$. In desert grasslands, the mean grass coverage was $17.1 \%$. These grasslands were located in the middle and west of IM and the Kunlun Mountains with grass coverage less than $20 \%$.

\subsection{Temporal changes of grass coverage in China}

The changing tendency of annual grass coverage was calculated based on equation 4 from 1982 to 2010 . We found that the total grass coverage increased by $0.17 \%$ per year (Figure $5 a)$. The most significant increases were found in the slope grasslands $(0.27 \%$ per year $)$, the alpine and sub-alpine meadows and the alpine and sub-alpine grasslands $(0.174 \%, 0.17 \%$ per year); and desert grasslands $(0.12 \%$ per year $)$. In the plain grasslands and meadows the lowest increase was observed $(0.11 \%$ per year, $0.10 \%$ per year, respectively; Table 2 and Figure 5a).

Table 2 Results of implementation of the grass coverage change significant test for different grassland types

\begin{tabular}{cccccccc}
\hline $\begin{array}{c}\text { Percentage } \\
(\%)\end{array}$ & $\begin{array}{c}\text { Alpine sub-alpine } \\
\text { meadow }\end{array}$ & $\begin{array}{c}\text { Slope } \\
\text { grassland }\end{array}$ & $\begin{array}{c}\text { Plain } \\
\text { grassland }\end{array}$ & $\begin{array}{c}\text { Desert } \\
\text { grassland }\end{array}$ & Meadow & $\begin{array}{c}\text { Alpine sub-alpine } \\
\text { grassland }\end{array}$ & $\begin{array}{c}\text { Total } \\
\text { grassland }\end{array}$ \\
\hline ESD & 5.53 & 1.64 & 5.26 & 2.76 & 6.27 & 1.22 & 4.10 \\
SD & 4.05 & 1.68 & 3.75 & 2.35 & 5.30 & 1.12 & 3.24 \\
NSD & 13.84 & 8.23 & 17.61 & 10.85 & 23.78 & 6.47 & 13.80 \\
NSI & 19.90 & 18.46 & 23.96 & 22.69 & 27.13 & 18.72 & 21.83 \\
SI & 9.85 & 11.63 & 9.55 & 11.97 & 8.35 & 15.02 & 11.00 \\
ESI & 46.83 & 58.36 & 39.87 & 49.39 & 29.17 & 57.46 & 46.03 \\
\hline
\end{tabular}

Note: ESD is the abbreviation of extremely significant decrease, SD is significant decrease, NSD is non-significant decrease, NSI is non-significant increase, SI is significant increase, and ESI is extremely significant increase.

Figure $5 \mathrm{~b}$ is the spatial distribution of significance test of grass cover change. Regions with ESI trend of the grass coverage were mainly distributed in the Mu Us Sandy Land, the Kunlun Mountains, western Tibet, western Xinjiang Uygur Autonomous Region and the Tianshan Mountains during 1982-2010. Areas with SI trend of the grass coverage were mainly located in the central part of the Tibetan Plateau and the middle part of the Hexi Corridor (Gansu Province). Areas with ESD trend of the grass coverage were mainly located in Hulun Buir, Tianshan and Altai Mountains, as well as in the southeast of the Tibetan Plateau. Regions with SD trend of grass coverage were restricted in the Horqin Sandy Land.

For each grassland type, Figure 5c shows the percentage of each grade of significance test as defined in section 2.5. Regions with the ESI and SI trends of grass coverage accounted for $46.03 \%$ and $11 \%$ of the total grassland area, respectively. Meanwhile, the area with ESD and SD trends accounted for only $4.1 \%$ and $3.24 \%$ of the total area, respectively. Regions with 

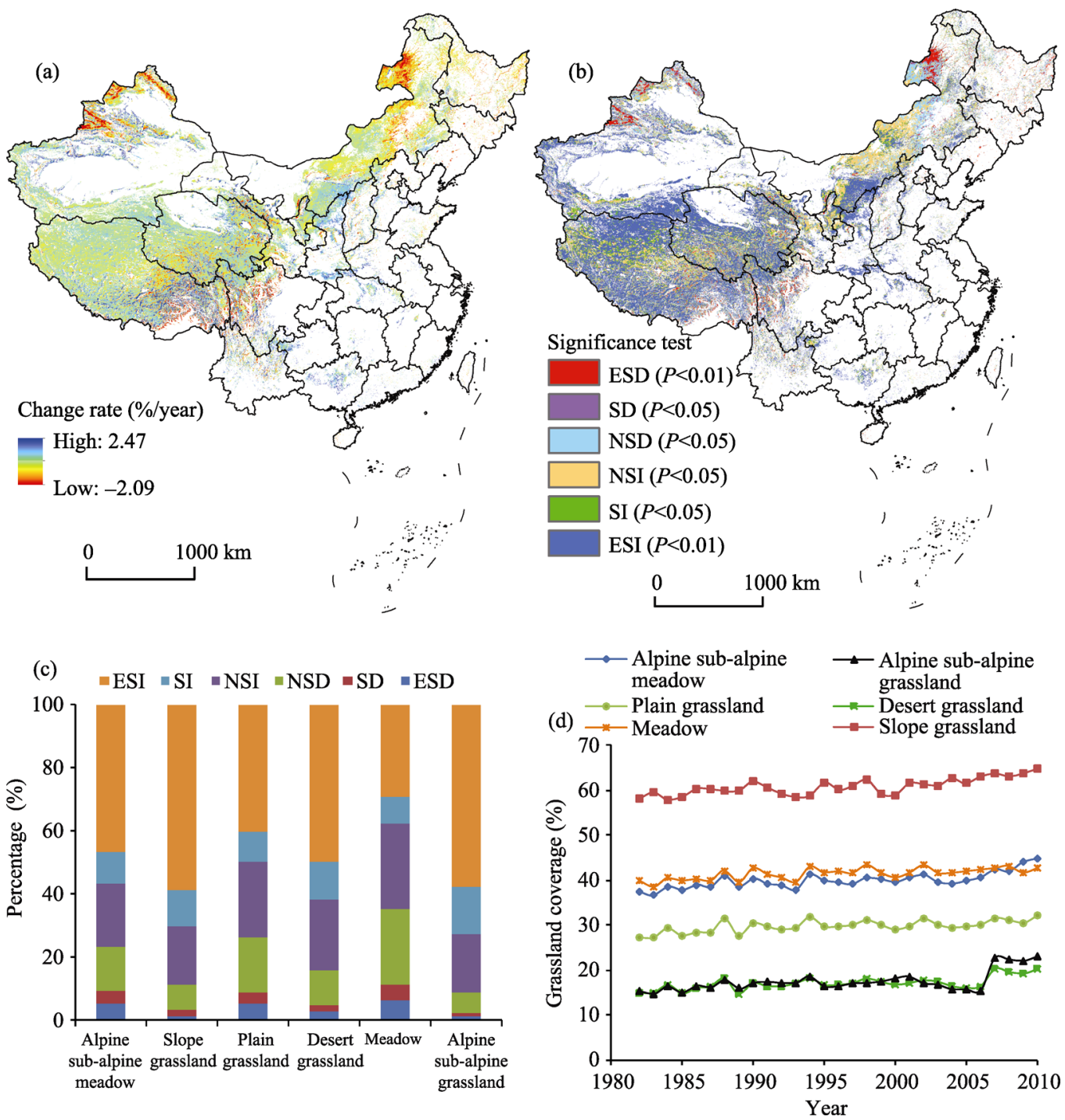

Figure 5 Dynamics of the China's grassland coverage from 1982 to 2010. Pattern of the grass coverage change (a), spatial distribution of significant test in China (b), the grade percentage of significant change of different types of grass coverage (c), and the nationwide inter-annual change of grass coverage (d)

no significant change accounted for $35.83 \%$ (NSI and NSD was $21.83 \%$ and $13.8 \%$, respectively). For the slope grasslands, the area percentage with ESI was the largest (58.36\%), followed by alpine and sub-alpine grasslands (57.46\%). Regions with an increasing trend of grass coverage were larger than that showing decreasing trend for all grassland types(Figure 5c). Overall, the grassland coverage had a fluctuated increasing trend in this period (Figure 5d).

\subsection{Correlation analysis of grass coverage with temperature and precipitation at the inter-annual time scale}

3.3.1 The correlation between grass coverage and temperature and precipitation for the total grasslands

During 1982-2010, temperature increased and precipitation decreased in most parts of China 
(Figure 6). 84\% of the total grassland area showed increasing temperature with a mean rate of $0.04^{\circ} \mathrm{C}$ per year. In addition, precipitation decreased in over $56 \%$ of the total grassland area with a mean decrease rate of $0.39 \mathrm{~mm}$ per year. Precipitation significantly decreased in the eastern part of IM, Northeast China, and Shanxi, Shaanxi, Sichuan and Yunnan provinces. In the arid regions of northwest China, such as Xinjiang, Tibet, Qinghai, central part of IM, temperature increased but precipitation also increased and the resulting effect of this type of climatic change on the water condition (the sign of the precipitation minus evapotranspiration differences) are unclear. The correlation coefficients of grass coverage with temperature and precipitation were not significant $(\mathrm{R}=0.21, \mathrm{P}>0.05 ; \mathrm{R}=0.10, \mathrm{P}>0.05$, respectively). The area percentage of the regions where grass coverage positively correlated with precipitation was $78.45 \%$ ( $13.08 \%$ with $0.01<\mathrm{P}<0.05$ and $18.2 \%$ with $\mathrm{P}<0.01)$. The area percentage of the regions where grass coverage positively correlated with temperature was $62.5 \%$ $(9.2 \%$ with $0.01<\mathrm{P}<0.05$ and $6.6 \%$ with $\mathrm{P}<0.01)$. This implies that, in China, the correlations of grass coverage with precipitation are higher than with temperature (Figure 7).

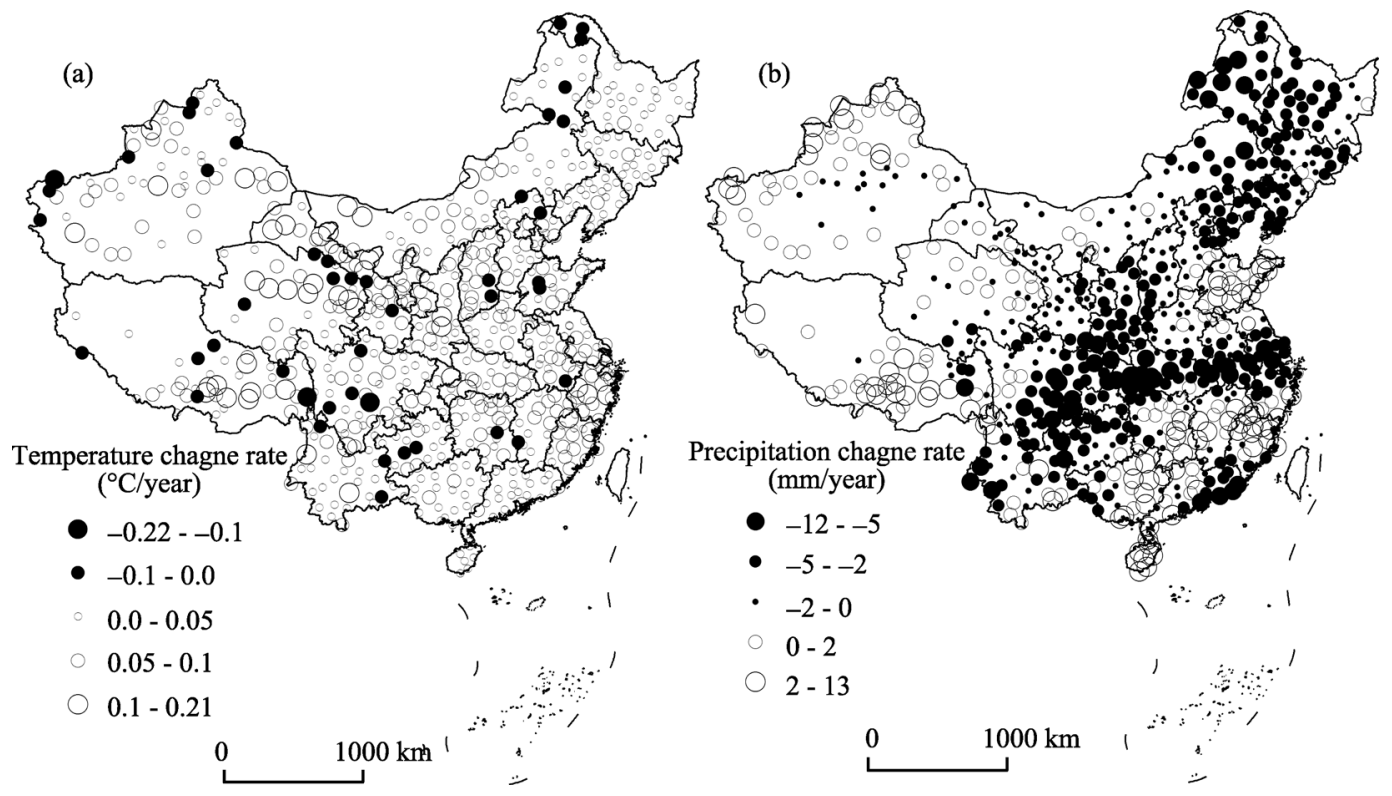

Figure 6 Changing trends of annual mean temperature and total precipitation in China from 1982 to 2010

The responses of grass coverage to temperature (Figure 7a) and precipitation (Figure 7b) have apparent spatial heterogeneities. The regional temperature in the central and western parts of the Tibetan Plateau, south of the Kunlun Mountains, and south of the Tianshan Mountains is the main restrictive factor for grass growth. Here, correlations between grass coverage and precipitation were above $0.35(\mathrm{P}<0.05)$, while temperature increased during 1982-2010 (Figure 6a). We found significant negative correlations $(\mathrm{P}<0.05)$ between grass coverage and temperature in western Xinjiang and the Hengduan Mountains (Figure 7a). These regions with high temperature, drought and little rain (Figure 6), especially the Hengduan Mountains, belonged to the dry-hot valley region, and precipitation is a limiting factor for vegetation growth. However, we observed significant positive correlations $(\mathrm{P}<0.05)$ between grass growth and precipitation in the Kunlun Mountains, western part of 
Tibet, and the northeastern and central parts of IM (Figure 7b). In these regions with desert grassland and little rain, precipitation was a restrictive factor for grass growth but it increased during 1982-2010 (Figure 6b). In the regions with abundant precipitation, such as the Three Rivers source region, central and southern parts of Tibet, we found negative correlations between grass coverage and precipitation. Possible reasons for these negative correlations may be that in the above mentioned regions with alpine and sub-alpine meadow, the moisture conditions were good but low temperatures restricted the grass growth. Besides, in the regions of Tianshan Mountains and Altai Mountains, negative correlations between grass coverage and precipitation are due to the fact that these are high altitudinal regions with abundant precipitation (and precipitation still increased during 1982-2010). Therefore, here temperature is a main limiting factor for grass growth.
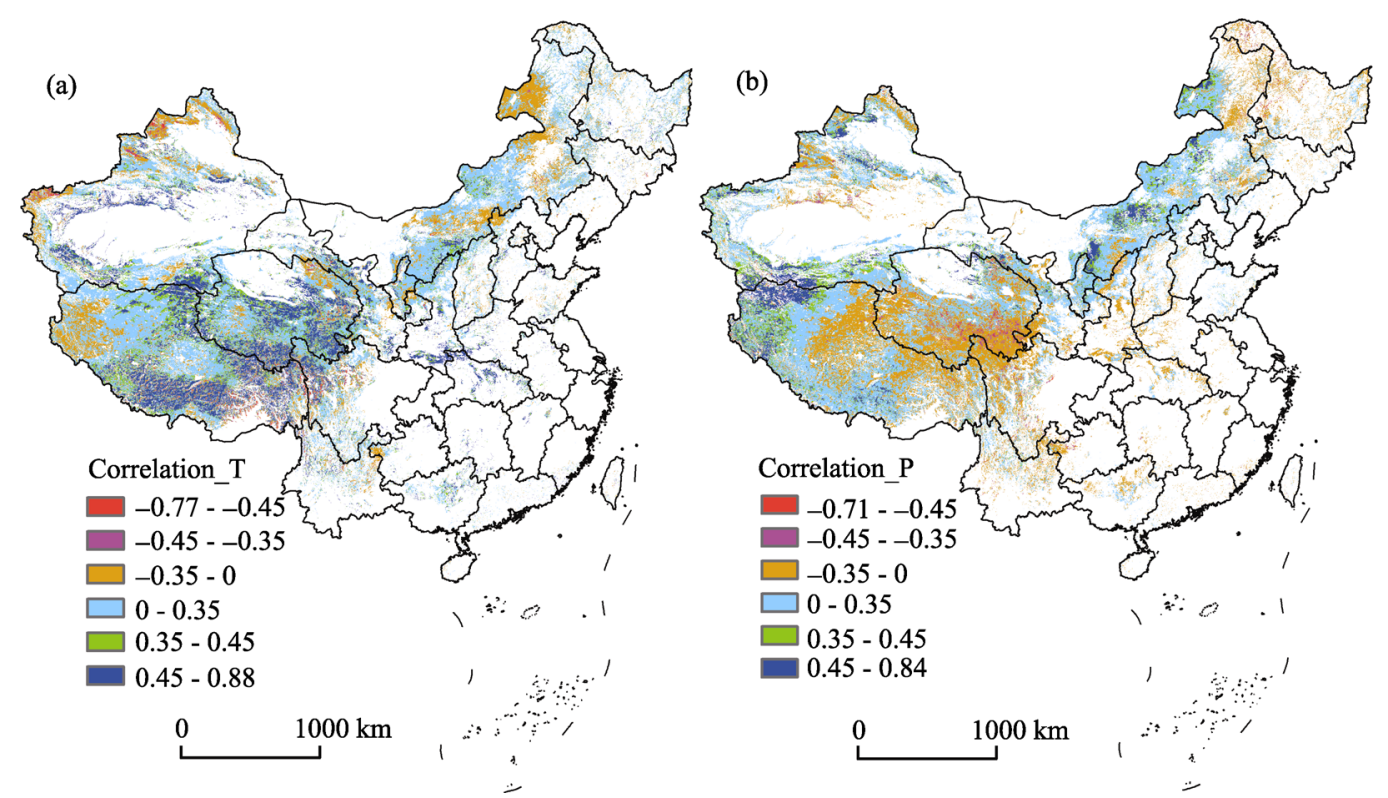

Figure 7 Correlations of grass coverage in China with temperature (a), and precipitation (b) from 1982 to 2010

3.3.2 The coupling relationship analysis between coverage and temperature, and precipitation in different grassland types

The correlation between vegetation coverage and temperature derived from 220 meteorological stations in grassland distribution regions represented the coordinate axis $\mathrm{X}$, coordinate axis $\mathrm{Y}$ was the correlation between vegetation coverage and precipitation as showed in Figure 8. The distribution pattern of scatters was different for the six grassland types. For alpine and sub-alpine meadow, scatters were located in the first, second and fourth quartiles (Figure 8a), and the correlation between coverage and temperature and precipitation was 0.24 and 0.005 , respectively. It indicated that grass growth was more affected by temperature. For slope grassland, scatters were distributed in the first and fourth quartiles (Figure $8 \mathrm{~b}$ ), which reflected the distribution characteristic. The correlation between coverage and temperature and precipitation was 0.28 and 0.01 , respectively. Plain grassland scatters, located in the first and second quartiles, mainly distributed in the central part of IM, east Ningxia and north Xinjiang with low precipitation. The correlation between coverage and 
temperature and precipitation was 0.14 and 0.16 , respectively. Desert grassland scatters were located in the first and fourth quartiles. The correlation between coverage and temperature and precipitation was 0.18 and 0.23 , respectively. Meadow scatters, located in the first, second and fourth quartiles, reflected the distribution characteristic of grassland. The correlation between coverage and temperature and precipitation was 0.15 and 0.08 , respectively. Alpine and sub-alpine grassland scatters were located in the first and second quartiles and the correlation between coverage and temperature and precipitation was 0.24 and 0.12 , respectively. In conclusion, grass coverage in plain grasslands and desert grasslands were more affected by precipitation than temperature; and the rest of four grassland types, grass coverage were more affected by temperature.
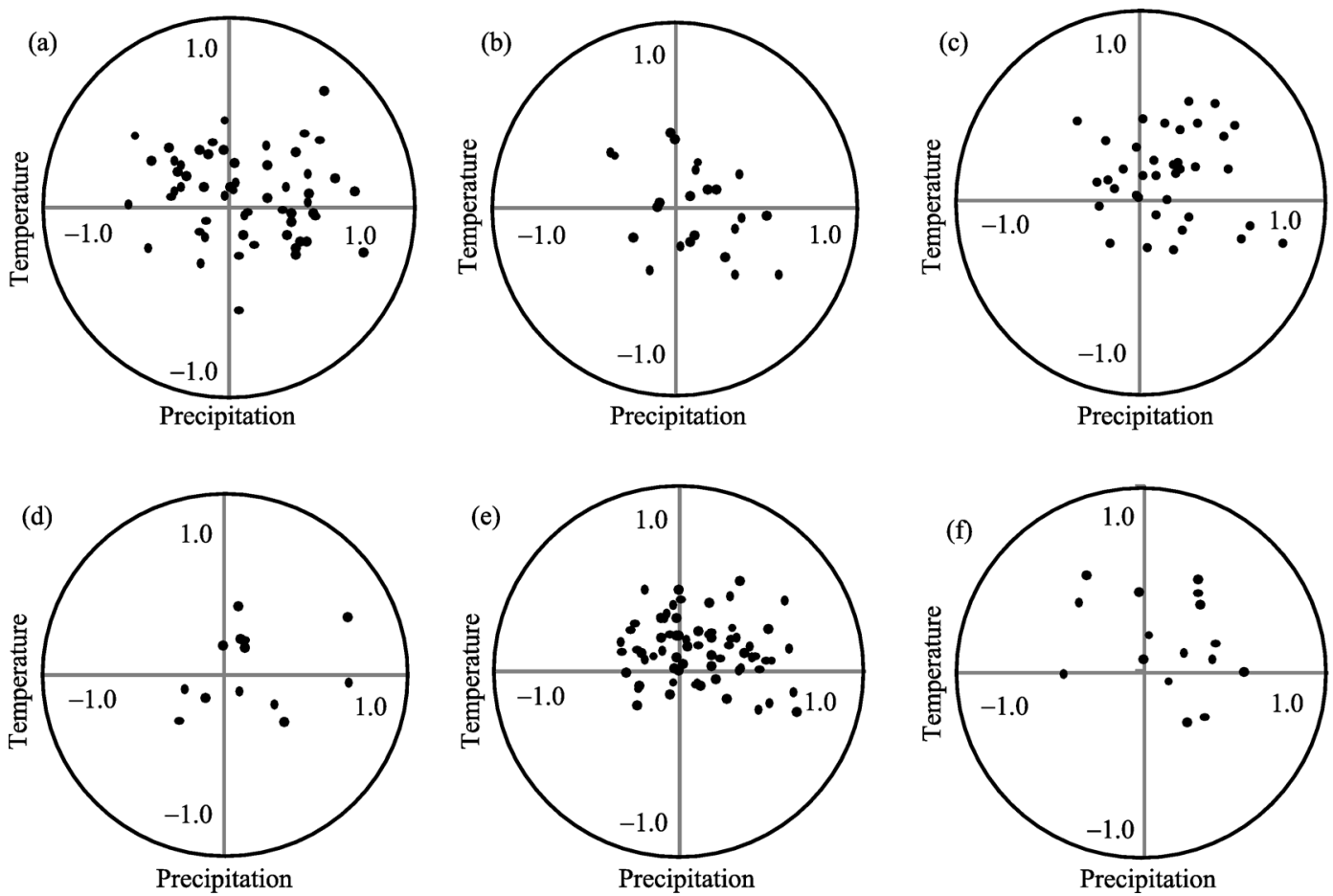

Figure 8 Distribution of correlation coefficient of temperature, precipitation and grassland coverage of different grassland types (a. denotes alpine and sub-alpine meadow; b. denotes slope grassland; c. denotes plain grassland; d. denotes desert grassland; e. denotes meadow; f. denotes alpine and sub-alpine grassland)

\subsection{Correlations of monthly grass coverage and climate factors; time-lag effect}

Monthly grass coverage, temperature and precipitation data during 1982-2010 were used to analyze correlations of the current month's grass coverage and the zero to three former months' temperature and precipitation (Figures 9 and 10). The mean correlation coefficient between the current month's grass coverage and current month's temperature was 0.8 (Figure 9a), which was much higher than that on inter-annual scale (0.21). Statistical analysis showed that, the area percentage of the regions with grass coverage positively correlated with temperature was $98 \%(1 \%$, with $0.01<\mathrm{P}<0.05$ and $96.3 \%$ with $\mathrm{P}<0.01)$. This indicated that the grass growth was strongly affected by monthly temperature variations. Fur- 
thermore, correlation between current month's grass coverage and the former one month's temperature was the largest $(0.90)$, followed by correlations with the former two months' temperatures $(0.74)$. Area percentage of the regions where vegetation coverage was positively correlated with former one to three months' precipitation was $99.5 \%, 98.0 \%$ and $85.60 \%$. These correlations showed an obvious time lag effect when the grass growth was more affected by the former one month's temperature than by the current month's temperature.
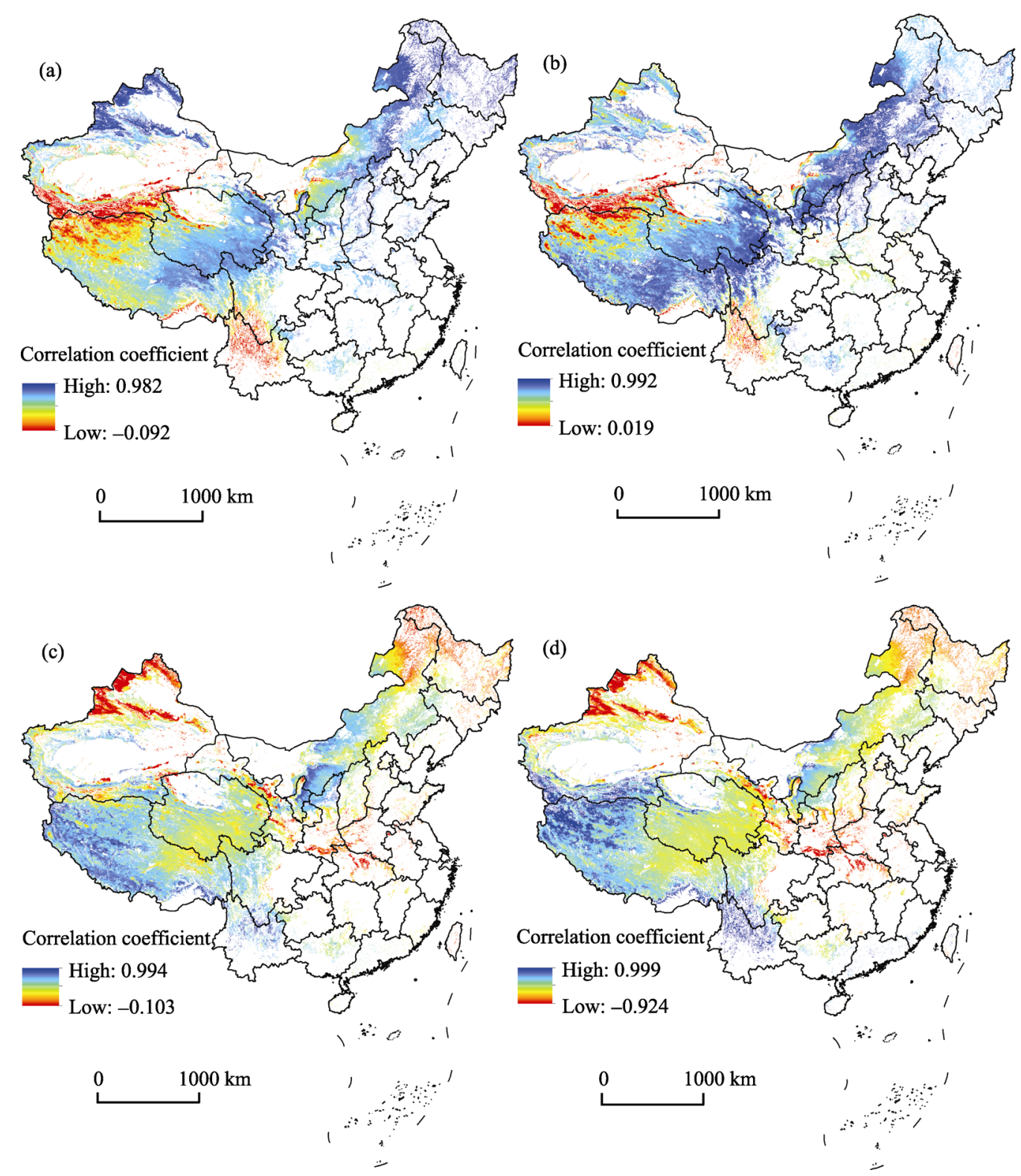

Figure 9 Correlation coefficients between current month's grass coverage and the current month's temperature (a), the former one month's temperature (b), the former two months' temperature (c), and the former three months' temperature $(\mathrm{d})$ 

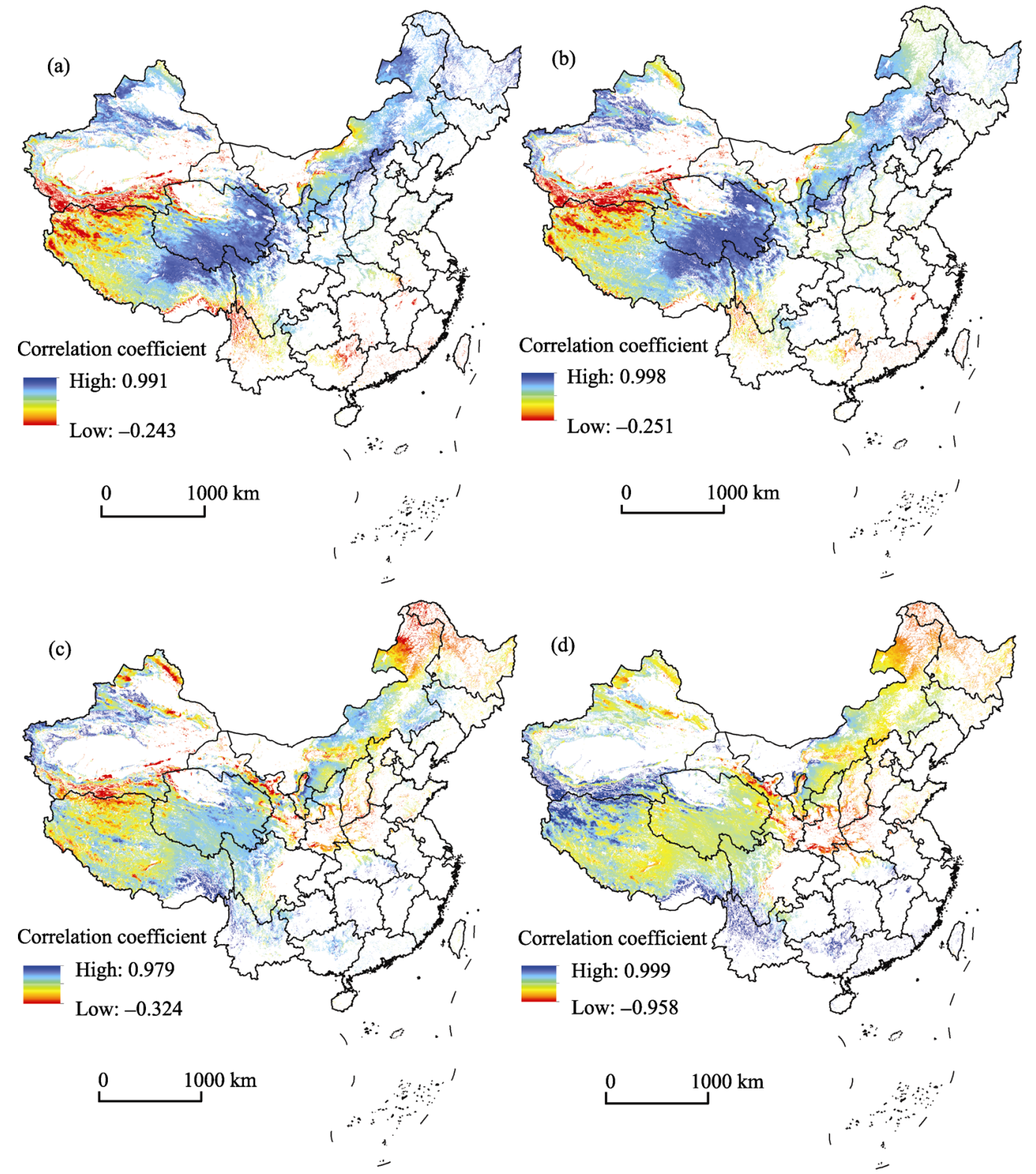

Low: -0.958

Figure 10 Correlation coefficients between current month's grass coverage and the current month's precipitation (a), the former one month's precipitation (b), the former two months' precipitation (c), and the former three months' precipitation (d)

The mean correlation coefficient between the grass coverage and current month's precipitation was 0.76 (Figure 9 a), much higher than that on the inter-annual time scale $(0.10)$. Area percentage of the regions with grass coverage positively correlated with precipitation was $98 \%$ (3.6\% with $0.01<\mathrm{P}<0.05$ and $93.6 \%$ with $\mathrm{P}<0.01$ ). Correlation between grass coverage and the former one month's precipitation was also the highest (Figure 10b). The correlations between the current month's grass coverage and former one to three months' precipitation equal to $0.79,0.56$, and 0.03 , respectively. Area percentage of the regions where vegetation coverage was positively correlated with former one to three months' precipitation 
was $99.5 \%, 99 \%$, and $45.57 \%$ respectively. Therefore, grass coverage also had one month time-lag with precipitation.

\subsection{Response of grass coverage in different grassland types to climatic variations}

Responses of grass coverage for different grassland types to temperature and precipitation are different; overall, correlations were the highest with the former one month's temperature and precipitation (Figure 11). For alpine and sub-alpine meadow, the correlations of the current month's grass coverage with the former zero to three months' temperature are 0.82 , $0.92,0.75$, and 0.28 respectively, and with precipitation being $0.81,0.85,0.61$, and 0.06 . Thus, for this type of grassland is mostly distributed across the Tibetan Plateau, both temperature and precipitation were responsible for the grass growth which was more affected by the former one month's temperature and precipitation (time-lag effect). For all the other five grassland types, the correlation of current month's grass coverage with former one month's temperature and precipitation was the largest, and the correlation between coverage and temperature were larger than that with precipitation as shown in Tables 3 and 4. Apparently, grass growth has one month time-lag effect to temperature and precipitation.
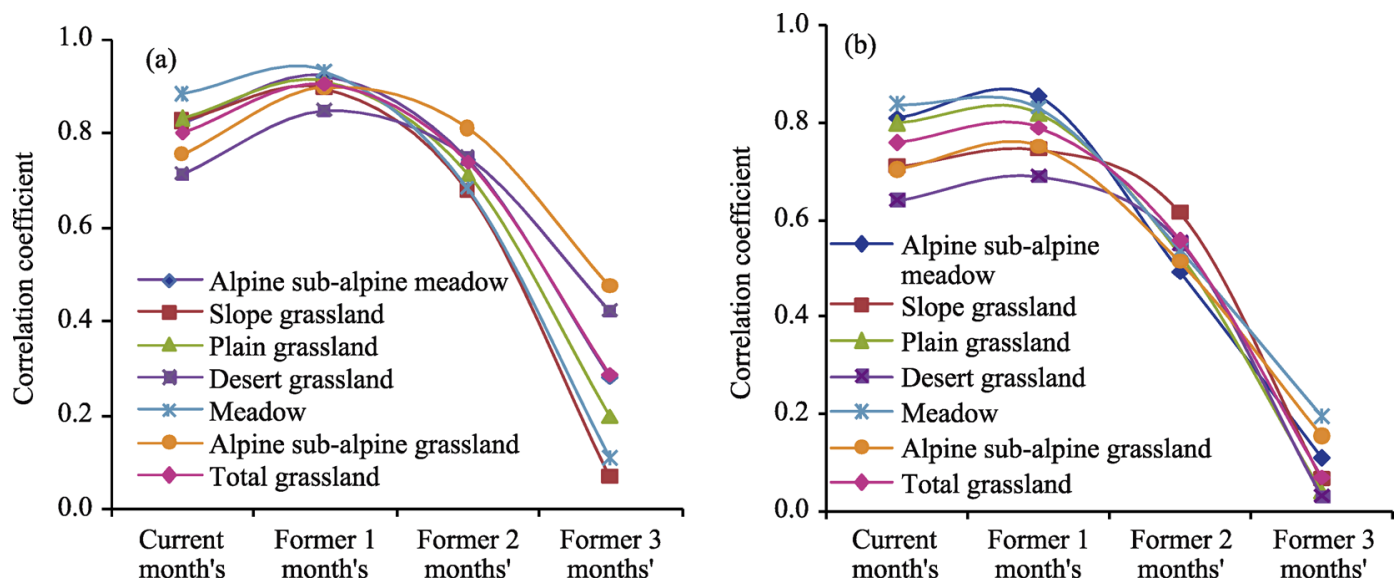

Figure 11 Correlation coefficients between current months' grass coverage for different grassland types and the current month's, former one month's, former two months' and former three months' temperature (a) and precipitation (b)

Table 3 Correlation coefficients between current month's grass coverage for different grassland types and the current month's, former one month's, former two months' and former three months' temperature

\begin{tabular}{ccccc}
\hline Temperature & $\begin{array}{c}\text { Current } \\
\text { month's }\end{array}$ & $\begin{array}{c}\text { Former one } \\
\text { month's }\end{array}$ & $\begin{array}{c}\text { Former two } \\
\text { months' }\end{array}$ & $\begin{array}{c}\text { Former three } \\
\text { months' }\end{array}$ \\
\hline Alpine sub-alpine meadow & 0.82 & 0.92 & 0.74 & 0.28 \\
Slope grassland & 0.83 & 0.90 & 0.68 & 0.07 \\
Plain grassland & 0.83 & 0.91 & 0.71 & 0.20 \\
Desert grassland & 0.71 & 0.85 & 0.75 & 0.42 \\
Meadow & 0.88 & 0.93 & 0.68 & 0.11 \\
Alpine sub-alpine grassland & 0.76 & 0.90 & 0.81 & 0.47 \\
Total grassland & 0.80 & 0.90 & 0.74 & 0.29 \\
\hline
\end{tabular}


Table 4 Correlation coefficients between current month's grass coverage for different grassland types and the current month's, former one month's, former two months' and former three months' precipitation

\begin{tabular}{ccccc}
\hline Precipitation & Current month's & Former one month's & Former two months' & Former three months' \\
\hline Alpine sub-alpine meadow & 0.81 & 0.85 & 0.49 & 0.11 \\
Slope grassland & 0.71 & 0.74 & 0.61 & 0.06 \\
Plain grassland & 0.80 & 0.82 & 0.53 & 0.04 \\
Desert grassland & 0.64 & 0.69 & 0.55 & 0.03 \\
Meadow & 0.84 & 0.83 & 0.54 & 0.19 \\
Alpine sub-alpine grassland & 0.70 & 0.75 & 0.51 & 0.15 \\
Total grassland & 0.76 & 0.79 & 0.56 & 0.07 \\
\hline
\end{tabular}

\section{Discussion}

Climate change has important effects on terrestrial vegetation. In the last two decades, vegetation coverage in most parts of China gradually increased (Fang et al., 2003). In Northwest China and the Tibetan Plateau, both temperature and precipitation showed increasing trends in the past 29 years that was consistent with Shi et al. (2007), who concluded that the pattern of climate change in Northwest China became warmer and more humid since the 1980s. In support of Fang et al. (2003), our findings found that the grassland coverage showed an increasing trend from 1982 to 2010 , being $78.9 \%$ of total grassland area of China and the areas of extremely significant and significant increases are mainly distributed in the above mentioned regions with warmer and wetter climate conditions.

In this study, there were no significant positive correlations between grass coverage with temperature and precipitation on the inter-annual time scale, while on the monthly time scale, these correlations were significant. The area percentage of regions where correlations of grass coverage with temperature and precipitation reached significant positive level (i.e., R-values were statistically significant at the 0.05 level) was $98 \%$ and $97.2 \%$ respectively. These findings were consistent with a study by Dai et al. (2010), who analyzed northwestern China's vegetation cover and concluded that on the monthly time scale, correlations between grass growth and climate factors were significant. Many studies concluded that the grass growth has significant correlation with precipitation (Li et al., 2006; Zhang et al., 2011; Piao et al., 2006; Sun et al., 2013). Our study concluded that the correlation between grass growth and temperature and precipitation was not significant at the annual time scale, but only on the monthly time scale correlation was significant. Moreover, in the most of grassland types (4 grasslands of 6 ), the grass growth variations are more affected by temperature than by precipitation.

However, grass growth is affected not only by climate conditions but is, also influenced by human activities, especially with human intervention intensity being increasing at present. In the past decade, the implementation of ecological restoration programs, such as the "Grain to Green" program since 1999 and "Returning of Grazing Land to Grassland" since 2003 have been leading to the restoration of grassland. This interventions decrease the sensitivity of grass growth to climate change to some extent, reducing correlation coefficient between grass coverage and climate factors. Zhang et al. (2011) analyzed spatial and temporal variations of vegetation coverage on the Loess Plateau during 1982-2009 and concluded that during 1982-1998, the annual mean NDVI showed strong correlations with 
temperature and precipitation. However, during 1999-2009, the annual mean NDVI increased significantly following the implementation of large-scale ecological restoration projects and the sensitivity of vegetation coverage to climate factors decreased. Mu et al. (2013) also reported there were weak correlations between vegetation coverage and climate factors on the inter-annual time scale. It looks like the vegetation coverage variations are a result of the combined actions of climate change and human activities (Xin et al., 2007; Zhang et al., 2013). To some extent, climate change plays a dominant role in global vegetation coverage variations, while human activities often execute decisive impacts on spatial-temporal change of vegetation (Chen et al., 2000). Human activities have a significant role in promoting grass growth and restoration, for example, Wang et al. (2009) found forbidding grazing and rotation grazing were beneficial to grassland restoration, in Maqu County; Ta et al. (2008) concluded that grass coverage increased by $97 \%$ after four years forbidding grazing in Alxa desert grassland. Besides, vegetation coverage significantly increased in Horqin Sandy Land after the implementation of ecological restoration program (Zhang et al., 2012). And the increase of grass net primary productivity was mostly attributed to ecological restoration programs (Zhou et al., 2013). These examples confirmed the anthropogenic role in the spatial and temporal variations of grass growth.

\section{Conclusions}

GIMMS NDVI and MODIS NDVI were used to calculate grass coverage from 1982 to 2010 and analyze its variations and correlation with major climatic variables (temperature and precipitation) at inter-annual and monthly time scales. The following conclusions can be drawn:

(1) The spatial distribution of grassland vegetation coverage in China had obvious heterogeneity with the grass coverage being higher in Southeast and lower in Northwest China. For the whole region, the mean grass coverage was 34\% during 1982-2010. The grass coverage was the highest in slope grassland, while the lowest in desert grassland.

(2) For $78.9 \%$ of the total grassland area of China, its grass coverage is increasing, and the mean coverage increased by $0.17 \%$ per year. The increase rates of grass coverage during the past 29 years for different grassland types can be sorted in the declining order as follows: slope grassland, alpine and sub-alpine meadow, alpine and sub-alpine grassland, desert grassland, plain grassland, and meadow. The slope grassland' grass coverage has the largest increase rate equal to $0.27 \%$ per year and the lowest rates in plain grassland and meadow $(0.11 \% /$ year and $0.1 \% /$ per year respectively).

(3) Area percentage of grass coverage with extremely significant and significant increase trend were $46.03 \%$ and $11 \%$, respectively; while the area percentage of grass coverage with extremely significant and significant decreases were only $4.1 \%$ and $3.24 \%$.

(4) On the inter-annual time scale, correlations of grass coverage with temperature and precipitation were not significant. The increases of both temperature and precipitation promote grass growth, but the responses of the grass coverage to climatic factors for different grassland types are different. The grass growth was more affected by temperature than by precipitation in alpine and sub-alpine grassland, alpine and sub-alpine meadow, slope grassland and meadow, while grass growth was more affected by precipitation in desert grassland and plain grassland. 
(5) On the monthly time scale, positive correlations of the grass coverage with temperature and precipitation were larger than that on the inter-annual scale and were statistically significant correlated. This indicates that seasonal fluctuations of the hydrothermal conditions have larger impacts on the grass growth than the inter-annual fluctuations. Overall, grass coverage was more affected by temperature than by precipitation (in all the 6 grassland types). There was one month time-lag effect and the correlations were the largest between the current month grass coverage and the former one month's temperature and precipitation.

\section{References}

Chen X, Tan Z, Schwartz M D et al., 2000. Determining the growing season of land vegetation on the basis of plant phenology and satellite data in northern China. International Journal of Biometeorology, 44(2): 97-101.

Chen Youqi, Peter H Verburg, Xu Bin, 2000. Spatial modeling of land use and its effects in China. Progress in Geography, 19(2): 116-127. (in Chinese)

Christensen L, Coughenour M B, Ellis J E et al., 2004. Vulnerability of the Asian typical steppe to grazing and climate change. Climatic Change, 63(3): 351-368.

Cui Linli, Shi Jun, Yang Yinming et al., 2009. Ten-day response of vegetation NDVI to the variations of temperature and precipitation in eastern China. Acta Geographica Sinica, 64(7): 850-860. (in Chinese)

Dai Shengpei, Zhang Bo, Wang Haijun et al., 2010. Spatio-temporal variation characteristics of vegetation cover in northwest China and its response to climate change. Remote Sensing Technology and Application, 25(1): 69-76. (in Chinese)

Dai S P, Zhang B, Wang H J et al., 2011. Vegetation cover change and the driving factors over northwest China. Journal of Arid Land, 3(1): 25-33.

Fang Jingyun, Piao Shilong, He Jinsheng et al., 2003. Vegetation of China invigorated in last 20 years. Science in China (Series C), 33(6): 554-565. (in Chinese)

Gan Chunying, Wang Xizhi, Li Baosheng et al., 2011. Changes of vegetation coverage during recent 18 years in Lianjiang river watershed. Scientia Geographica Sinica, 31(8): 1019-1024. (in Chinese)

Gutman G, Ignatov A, 1998. The derivation of the green vegetation fraction from NOAA/AVHRR data for use in numerical weather prediction models. International Journal of Remote Sensing, 19(8): 1533-1543.

Hall F G, Huemmrich K F, Goetz S J et al., 1992. Satellite remote sensing of surface energy balance: Success, failures, and unresolved issues in FIFE. Journal of Geophysical Research: Atmospheres (1984-2012), 97(D17): 19061-19089.

Keeling C D, Chin J, Whorf T P, 1996. Increased activity of northern vegetation inferred from atmospheric $\mathrm{CO}_{2}$ measurements. Nature, 382(6587): 146-149.

Li Xia, Li Xiaobing, Wang Hong et al., 2006. Impact of climate change on temperate grassland in northern China. Journal of Beijing Normal University (Natural Science), 42(6): 618-623. (in Chinese)

Li Xiaobing, Shi Peijun, 2000. Sensitivity analysis of variation in NDVI, temperature and precipitation in typical vegetation types across China. Acta Phytoecologica Sinica, 24(3): 379-382. (in Chinese)

Li Z, Kafatos M, 2000. Interannual variability of vegetation in the United States and its relation to El Nino/Southern Oscillation. Remote Sensing of Environment, 71(3): 239-247.

Luo Ling, Wang Zongming, Song Kaishan et al., 2009. Research on the correlation between NDVI and climatic factors of different vegetations in the Northeast China. Acta Botanica Boreali-Occidentalia Sinica, 29 (4): 800-808. (in Chinese)

Mu S J, Yang H F, Li J L et al., 2013. Spatio-temporal dynamics of vegetation coverage and its relationship with climate factors in Inner Mongolia, China. Journal of Geographical Sciences, 23(2): 231-246.

Myneni R B, Keeling C D, Tucker C J et al., 1997. Increased plant growth in the northern high latitudes from 1981 to 1991. Nature, 386(6626): 698-702.

Parmesan C, Yohe G, 2003. A globally coherent fingerprint of climate change impacts across natural systems. Nature, 421(6918): 37-42.

Piao Shilong, Fang Jingyun, 2001. Dynamic vegetation cover change over the last 18 years in China. Quaternary Research, 21(4): 294-302. (in Chinese)

Piao S L, Fang J Y, Ji W et al., 2004. Variation in a satellite-based vegetation index in relation to climate in China. Journal of Vegetation Science, 15(2): 219-226.

Piao S L, Mohammat A, Fang J Y et al., 2006. NDVI-based increase in growth of temperate grasslands and its responses to climate changes in China. Global Environmental Change, 16(4): 340-348. 
Ran Y, Li X, Lu L, 2010. Evaluation of four remote sensing based land cover products over China. International Journal of Remote Sensing, 31(2): 391-401.

Ren Jizhou, Liang Tiangang, Lin Huilong et al., 2011. Study on grassland's response to global climate change and its carbon sequestration potentials. Acta Prataculturae Sinica, 20(2): 1-22. (in Chinese)

Roerink G J, Menenti M, Soepboer W et al., 2003. Assessment of climate impact on vegetation dynamics by using remote sensing. Physics and Chemistry of the Earth, Parts A/B/C, 28(1): 103-109.

Shi Y, Shen Y, Kang E et al., 2007. Recent and future climate change in Northwest China. Climatic Change, 80(3/4): 379-393.

Sun Hongyu, Wang Changyao, Niu Zheng et al., 1998. Analysis of the vegetation cover change and the relationship between NDVI and environmental factors by using NOAA times series data. Journal of Remote Sensing, 2(3): 204-210. (in Chinese)

Sun J, Cheng G W, Li W P et al., 2013. On the variation of NDVI with the principal climatic elements in the Tibetan Plateau. Remote Sensing, 5(4): 1894-1911.

Sun Yanling, Guo Peng, Yan Xiaodong et al., 2010. Dynamics of vegetation cover and its relationship with climate change and human activities in Inner Mongolia. Journal of Natural Resources, 25(3): 407-414. (in Chinese)

Ta Lateng, Liu Julan, Li Ji et al., 2008. Monitoring on the effect of returning grazing desert to grassland in Alashan. Pratacultural Science, 25(2): 124-127. (in Chinese)

Tang Haiping, Cheng Yufu, 2003. Inter-annual variability of NDVI and its relation to climate in Northeast China transect. Quaternary Research, 23(3): 318-325. (in Chinese)

Waker B, Steffen W, 1997. IGBP Science No.1: A Synthesis of GCTE and Related Research. Stockholm: IGBP, $1-24$.

Wang Jing, Guo Ni, Cai D H et al., 2009. The effect evaluation of the program of restoring grazing to grasslands in Maqu County. Acta Ecologica Sinica, 29(3): 1276-1284. (in Chinese)

Weltzin J F, Loik M E, Schwinning S et al., 2003. Assessing the response of terrestrial ecosystems to potential changes in precipitation. Bioscience, 53(10): 941-952.

Wu Ruifen, Huo Zhiguo, Cao Yanfang et al., 2009. Phenophase change of typical herbaceous plants in Inner Mongolia in spring and its response to climate warming. Chinese Journal of Ecology, 28(8): 1470-1475. (in Chinese)

Xin Z, Xu J, Zheng W, 2008. Spatiotemporal variations of vegetation cover on the Chinese Loess Plateau (1981-2006): Impacts of climate changes and human activities. Science in China Series D: Earth Sciences, 51(1): 67-78.

Xin Zhongbao, Xu Jiongxin, Zheng Wei, 2007. Spatiotemporal variations of vegetation cover on the Chinese Loess Plateau (1981-2006): Impacts of climate changes and human activities. Science in China: Earth Sciences, 37 (11): 1504-1514. (in Chinese)

Yang Yuanhe, Piao Shilong, 2006. Variations in grassland vegetation cover in relation to climatic factors on the Tibetan Plateau. Journal of Plant Ecology, 30(1): 1-8. (in Chinese)

Zhang Baoqing, Wu Pute, Zhao Xining, 2011. Detecting and analysis of spatial and temporal variation of vegetation cover in the Loess Plateau during 1982-2009. Transactions of the CSAE, 27(4): 287-294. (in Chinese)

Zhang F, Tiyip T, Ding J L et al., 2013. Vegetation fractional coverage change in a typical oasis region in Tarim River Watershed based on remote sensing. Journal of Arid Land, 5(1): 89-101.

Zhang G L, Dong J W, Xiao X M et al., 2012. Effectiveness of ecological restoration projects in Horqin Sandy Land, China based on SPOT-VGT NDVI data. Ecological Engineering, 38(1): 20-29.

Zhang Geli, Xu Xingliang, Zhou Caiping et al., 2011. Responses of vegetation changes to climatic variations in Hulun Buir Grassland in past 30 years. Acta Geographica Sinica, 66(1): 47-58. (in Chinese)

Zhang J, Ge J P, Guo Q X, 2001. The relation between the change of NDVI of the main vegetational types and the climatic factors in the northeast of China. Acta Ecologica Sinica, 21(4): 522. (in Chinese)

Zhang J, Zhang Q, Yang L et al., 2006. Seasonal characters of regional vegetation activity in response to climate change in West China in recent 20 years. Journal of Geographical Sciences, 16(1): 78-86.

Zhao Maosheng, Fu Congbin, Yan Xiaodong, 2001. Study on the relationship between different ecosystems and climate in China using NOAA/AVHRR data. Acta Geographica Sinica, 56(3): 287-296. (in Chinese)

Zhou L, Tucker C J, Kaufmann R K et al., 2001.Variations in northern vegetation activity inferred from satellite data of vegetation index during 1981 to 1999. Journal of Geophysical Research: Atmospheres (1984-2012), 106(D17): 20069-20083.

Zhou W, Li J L, Mu S J et al., 2013. Effects of ecological restoration-induced land-use change and improved management on grassland net primary productivity in the Shiyanghe River Basin, north-west China. Grass and Forage Science, doi: 10.1111/gfs.12073. 